\title{
LA REFORMA CONSTITUCIONAL CUBANA (12-6-92) Y LA NUEVA LEY ELECTORAL (72/92)
}

ANA POYAL COSTA

Facultad de Ciencias Políticas y Sociología UNED 
SUMARIO

I. Introducción.-II. Procedimiento de Reforma Constitucional. Art. 141.-III. Génesis de la Reforma Constitucional.—IV. La Ley de Reforma Constitucional. -V. La nueva Ley Electoral 72/92.-IV. Consideraciones finales. 


\title{
LA REFORMA CONSTITUCIONAL CUBANA (12-6-92) Y LA NUEVA LEY ELECTORAL (72/92)
}

\author{
POR \\ ANA POYAL COSTA \\ Facultad de Ciencias Políticas y Sociología. UNED
}

\section{INTRODUCCIÓN}

La Constitución Socialista Cubana vigente, aprobada por referéndum popular y proclamada el 24 de febrero de 1976, fundamenta el principio de su organización estatal en la concepción marxista leninista de la unidad del poder político y la división de funciones entre los distintos órganos del Estado Socialista. El sistema de partido único es la piedra angular del régimen político cubano, y no impide que politólogos, juristas y teóricos del régimen argumenten y diserten sobre la legitimidad democrática del sistema:

Entre las afirmaciones básicas que se utilizan está que "unipartidismo en Cuba significa mantener la unidad del pueblo e impedir que se debilite y fragmente nuestra sociedad", o bien que "la esencia democrática de sus instituciones reside en la participación popularn'.

Citemos brevemente, para situar nuestro estudio, que el Órgano Supremo del Poder Estatal, según dispone el artículo 67 de la Constitu-

1 Partido Comunista, Plataforma Programática, Departamento de Orientacion Revolucionaria del CC del PCC, La Habana, 1976. 1960.

Roca Calderio, Blas: Los Fundamentos del Socialismo en Cuba, La Habana,

HARneCKER, Marta: Cuba: ¿Dictadura o democracia?, Siglo XXI, México, 1975.

Sweezy, Paul, y Huberman, Leo: Socialism in Cuba, Monthly Review Press, Nueva York, 1969. 
ción, reside en la Asamblea Nacional del Poder Popular, órgano electivo, integrado por representantes de todas las Asambleas Municipales del Poder Popular en el país. Del seno de la Asamblea Nacional del Poder Popular, que se renueva cada 5 años, se elige el Consejo de Estado, órgano colegiado que entre un período y otro de sesiones de la Asamblea Nacional asume funciones de éste, según lo dispuesto en la Constitución.

Fue a inicios de la década del setenta cuando se comienzan a dar los primeros pasos en el proceso de institucionalización del país. Pero el Gobierno Revolucionario, desde su comienzo, habia recurrido al componente de la participación popular como esencia democrática del siste$\mathrm{ma}^{2}$. A través de los mecanismos constituidos por las organizaciones de masas, se articulaba la participación del pueblo en la toma de decisiones, que con un fuerte componente populista, tenía lugar en reuniones masivas en la Plaza de la Revolución.

Pero en el proceso de institucionalización que se inicia a partir de 1970 se dan diferentes etapas hasta culminar en la promulgación del texto constitucional. Así, a finales de 1972 se reestructura el Consejo de Ministros y se crea su Comité Ejecutivo. Dentro del Partido se precisaron y delimitaron las funciones y responsabilidades de todo su aparato, a todos los niveles, desde la instancia municipal hasta el Comité Central y se desarrollaron distintas leyes como la Ley de Organización del Sistema Judicial, la Ley de Procedimiento Civil y Administrativo, la Ley de Procedimiento Penal y el Código de la Familia.

Tuvo lugar un período de prueba en la provincia de Matanzas de la forma de organización del Estado cubano, cuyos resultados fueron estimados positivos por el I Congreso del PCC, que dio paso a su extensión a todo el país en 1976 con la instauración de los Órganos de Poder Popular $^{3}$. Tras la Constitución se continuó el proceso de estructura política con la Ley de la División Político-Administrativa del 3-7-76, en la cual se establecieron los 169 municipios y las 14 provincias, así como la Ley Electoral (1305) de 7-7-76.

2 Véase Isabel Cristina VARONA: "La reforma constitucional y los cambios en el sistema electoral. Perspectiva y posibilidades de una mayor democratización", Revista Cubana de Derecho, n. 7, 1992.

3 Castro Ruz, Fidel, Informe Central al Primer Congreso del Partido Comunista Cubano, Editorial de Ciencias Sociales, La Habana, 1985.

Partido Comunista de Cuba, Tesis y Resoluciones del I Congreso, Editorial de Ciencias Sociales, La Habana, 1978. 
Han transcurrido 16 años ${ }^{4}$ desde la proclamación del Texto constitucional y se ha hecho patente la necesidad de modificar parte del texto e incluir una serie de cambios en el sistema político, que se han plasmado fundamentalmente en la Ley de Reforma Constitucional y en la aprobación de una nueva Ley Electoral, cuya génesis, alcance y desarrollo vamos a exponer a continuación, partiendo de un punto de vista descriptivo de la realidad política cubana y obviando otros análisis e interpretaciones que por si solas ya serian materia para un estudio.

\section{II.. PROCEDIMIENTO DE REFORMA CONSTITUCIONAL: ART. 141}

La cláusula de reforma de la Constitución de la República de Cuba está contenida en el artículo 141, estableciendo un procedimiento especial para las modificaciones legislativas que afecten a la Constitución, pero en todo momento está en concordancia con la concepción de la existencia de un órgano máximo de poder estatal.

El artículo 141 dice así:

"Esta Constitución sólo puede ser reformada, total o parcialmente, por la Asamblea Nacional del Poder Popular mediante acuerdo adoptado, en votación nominal, por una mayoria no inferior a las dos terceras partes del número total de sus integrantes.

Si la reforma es total o se refiere a la integración y facultades de la Asamblea Nacional del Poder Popular o de su Consejo de Estado o a derechos y deberes consagrados en la Constitución, requiere, además, la ratificación por el voto favorable de la mayoría de los ciudadanos con el derecho electoral, en referendo convocado al efecto por la propia Asamblea."

Hay que señalar que el art. 4 establece que: «En la República de Cuba todo el poder pertenece al pueblo trabajador que lo ejerce por medio de las Asambleas del Poder Popular y demás órganos del Estado que de ellos se derivan, o bien directamente". En términos declarativos queda

EcksteIn, Susan, "The impact of the Cuban Revolution: A comparative Perspective", Comparative Studies in Society and History, $n^{\circ} 3$, julio, págs. 502-534, 1986.

4 Castro Ruz, Raúl, La Constitución que hoy proclamamos es manifestación y sentir de la voluntad de todo nuestro pueblo, Imprenta Federico Engels de Propaganda del PCC, La Habana, 1976. 
establecido que la soberanía nacional reside en el pueblo cubano, aunque su ejercicio cotidiano se realiza a través de los órganos estatales que según la justificación política de la República Cubana se ha dado el propio pueblo cubano en su texto constitucional, los cuales actúan en representación del pueblo, pero se reserva además la posibilidad de que ese poder se ejerza directamente ${ }^{5}$.

Partiendo del principio de la unidad de poder, fundamento jurídico de la República socialista cubana, el artículo 67 establece que: "La Asamblea Nacional del Poder Popular es el órgano supremo de poder del Estado. Representa y expresa la voluntad soberana de todo el pueblo trabajador».

Se insiste, pues, en esta norma en que todos los demás órganos estatales quedan directa o indirectamente bajo la subordinación de este órgano supremo, el cual, reitera este artículo, actúa por delegación de la mayoría de la sociedad, es decir, los trabajadores.

Asimismo, el artículo 68 es básico para la argumentación que justifica la potestad reformadora de la Asamblea Nacional del Poder Popular, pues establece que:

"La Asamblea Nacional del Poder Popular es el único órgano con potestad constituyente y legislativa de la República.»

Por otra parte, se especifica y se afirma que la potestad constituyente radica en el propio pueblo, y no en sus órganos representativos; la contradicción que parece evidenciarse se pretende salvar subrayando que la Asamblea Nacional no puede ejercer esta facultad reformadora constitucional de modo absoluto, sino que han de darse unos requisitos previos que el artículo 141 establece.

Asimismo, reconociendo las posibilidad de reformar en cualquier sentido la Constitución, incluso en su totalidad, como facultad en primera instancia de la Asamblea Nacional del Poder Popular, el propio texto garantiza para el pueblo, en determinados casos, el ejercicio de su soberanía constituyente, mediante referéndum en los cuales deberá pronunciarse a favor o en contra de los cambios dispuestos por su asamblea.

5 Además de los plebiscitos y referéndum previstos en la Constitucion, como ejemplo máximo de tal ejercicio de poder directo, se enumera la Asamblea de Rendición de Cuentas, que se realizan ordinariamente dos veces al año y en las cuales los representantes populares responden a las proposiciones y requerimientos que sobre su labor y las del órgano Imunicipal, provincial o nacional) a que pertenece, le hacen sus electores. 
Puede decirse entonces que, en ejercicio por delegación de la soberanía popular, la Asamblea Nacional del Poder Popular puede adoptar acuerdos que modifiquen la Ley Fundamental en cuanto estructura y funciones del Consejo de Ministros y otras instituciones de la Administración del Estado y de los órganos locales del poder popular, en relación con la Fiscalia y Tribunales y el sistema electoral, pero no puede ejercer esta facultad independientemente del poder constituyente para la modificación total de la Constitución o para modificar las facultades y composición de los órganos supremos del poder estatal, o efectuar deberes y derechos consagrados como fundamentales en la propia Constitución.

Pero llama la atención que la propia cláusula de reforma no esté expresamente incluida entre los elementos que no puede modificar independientemente la Asamblea Nacional del Poder Popular.

Según el profesor J. CANDÍA FERREIRA ${ }^{6}$, esta amplitud de las facultades alegadas a los órganos estatales ya constituidos se basa en dos criterios esenciales:

a) La Asamblea Nacional del Poder Popular es el supremo órgano del poder, que lo ejerce en representación de todo el pueblo, no comparte su supremacía con otros "poderes" u órganos estatales $y$, siendo el máximo y único depositario de la soberanía nacional, no debe quedar sujeto a limitaciones, salvo las que se han considerado imprescindibles reservar para ejercitarlas por el propio pueblo constituyente.

b) La Constitución vigente, no debe cerrar el paso hacia la evolución constituciọnal de las siguientes generaciones, estableciendo difíciles y complicados sistemas de reforma, sino que por el contrario, tomando en cuenta el desarrollo dialéctico de la vida social debe facilitar ese desarrollo.

Por otra parte, en cuanto a la posibilidad de que el propio órgano legislativo constituido modifique algunos preceptos de la Ley Fundamental con total independencia, según CANDÍA FERREIRA ${ }^{7}$, hay que tomar en cuenta que en realidad no todas las normas que se incluyen en la Constitución tienen el carácter de normas fundamentales, como también señala el profesor CARPIZO": "No todas las normas incluidas en la Cons-

- Véase José Candia Ferreira, "Comentarios acerca de la Reforma Constitucional", Revista Cubana de Derecho, n. $27,1992$.

7 Ibidem.

- Carpizo, Jorge, Estudios Constitucionales, UNAM, pág. 63, México, 1980. 
titución desde el punto de vista material son realmente de naturaleza constitucional; es decir, principios rectores, bases, columnas del orden jurídico, pero una buena parte de ellas sí tienen esa caracteristica y son las que se refieren: a los derechos humanos en general, a la organización, funciones y limitaciones del gobierno y al proceso de creación de las otras normas".

De aqui que se justifique, y sea posible e incluso necesario, la existencia de dos procedimientos especiales, aunque uno más simplificado que el otro, para aprobar las reformas, atendiendo a la importancia material de los preceptos afectados.

Excluyendo específicamente los aspectos que según el artículo 141 requieren para ser reformados la celebración de un referéndum, podrían modificarse sin ese requisito las siguientes cuestiones:

- Los fundamentos políticos, sociales y económicos (Capítulo I).

- La ciudadanía (Capítulo II).

- La Familia (Capítulo III).

- La Educación y Cultura (Capítulo IV).

- Los Principios de Organización y Funcionamiento de los Órganos Estatales (Capítulo VII).

- Los Órganos Supremos del Poder Popular, excepto las concernientes a la integración y atribuciones de la Asamblea $\mathrm{Na}$ cional o de su Consejo de Estado (Capítulo VIII).

- Los Órganos Locales del Poder Popular (Capítulo IX).

- Los Tribunales y la Fiscalía (Capítulo X).

- El Sistema Electoral (Capítulo XI).

- El propio artículo 141 referido a la Reforma de la Constitución (Capitulo XII).

Por su parte, otro grupo de juristas han formulado la tesis de que pueden modificarse también por la Asamblea, sin necesidad de su ratificación en un referéndum, los preceptos contenidos en los Capítulos que tratan de la Igualdad (Capitulo V) y los Derechos, Deberes y Garantías Fundamentales (Capítulo VI), siempre que no limiten, restrinjan o eliminen el ejercicio de esos derechos y deberes.

Al respecto se argumenta que el requisito de procedimiento adicional (la aprobación en referéndum de las modificaciones antes expre- 
sadas) en to que se refiere a los deberes y derechos tiene el propósito de defenderlos y evitar que sean disminuidos o limitados por un órgano cuyas facultades de reforma de la Constitución son delegadas por el pueblo; y en cuanto a las facultades de dichos órganos y a la calidad de los que los integran, el citado requisito de procedimiento tiene el propósito de dificultar las modificaciones encaminadas a que dichos órganos intercambien con otros o disminuyan sus atribuciones.

Hasta ahora nos hemos referido a cómo está fijado el procedimiento de reforma en la Constitución de 1976, en el artículo 141, y en su breve análisis hemos aludido a la justificación de su redacción y de su contenido. Citaremos ahora que sólo ha habido un caso de reforma constitucional anterior a la de 12-6-92, que analizaremos a continuación ${ }^{9}$. Se trata de una modificación de la Constitución cubana que tuvo como objeto el cambio de nombre de una parte del archipiélago cubano, la segunda isla en extensión, llamada hasta entonces Isla de Pinos, y que fue llamada a partir de entonces como Isla de la Juventud, con motivo de la celebración en Cuba del IX Festival Mundial de la Juventud y los Estudiantes.

Para hacer oficial esta reforma hubo de modificarse el apartado a) del artículo 10 de la Constitución, que se referia al territorio nacional y mencionaba, Isla de Pinos; además de esta modificación, en la Ley de Reforma Constitucional de 28 de junio de $1978^{10}$ se modificaron los artículos que fueron necesarios de la Ley $1304 / 76$ sobre la división político-administrativa del pais. Para esta modificación de la Constitución no fue necesario recurrir al mecanismo de ratificación popular, y se modificó la constitución por el procedimiento más simple.

\section{GÉNESIS DE LA REFORMA CONSTITUCIONAL}

Si, como es sabido, motivos para una reforma de un texto constitucional son la necesidad de adaptar la norma constitucional a la realidad cambiante, como resultado de la permanente interacción " que existe en-

- Véase Isabel Cristina VARONa, "La reforma Constitucional y los...", Revista Cubana de Derecho, n. 7, 1992.

10 Véase Candia Ferreira, José, "Comentarios acerca de la Reforma Constitucional", Revista Cubana de Derecho, n. 7, 1992.

1 Poyal Costa, Ana, La interacción entre norma constitucional y realidad en la dinámica de los sistemas políticos, Universidad Complutense de Madrid, Madrid, 1991. 
tre texto constitucional y las diferentes esferas de la realidad, económica, política y social, evitando así la disociación entre realidad y un texto obsoleto, envejecido y convertido en letra muerta, también los años de vigencia de un texto nos muestran las lagunas e insuficiencias de que pueda adolecer y que conviene subsanar.

En el caso concreto de la Constitución Socialista Cubana, es más evidente la necesidad de una reforma ya que los cambios ocurridos en el mundo socialista y las extinción de la Unión Soviética convierten en obsoletas algunas referencias que se incluyen en el texto constitucional. Además, los cambios y modificaciones económicos que se han introducido en el régimen cubano, como diferentes tipos de asociación de empresas mixtas y de inversión extranjera, las diferentes formas de propiedad y la regulación del comercio exterior, hacen necesaria la reforma del texto, ya que aparecía reflejando una realidad distinta. Asimismo, las nuevas concepciones de la ciudadania, derechos y obligación de extranjeros, la regulación del estado de emergencia y otra serie de instituciones, que están presentes en la generalidad de las constituciones modernas, hacen preciso que el texto constitucional sea modificado.

Pero aun siendo éstas las razones generales de la Reforma llevada a cabo, el verdadero motor del proceso de reforma radica en el IV Congreso del Partido. EI IV Congreso del Partido ${ }^{12}$ y sus recomendaciones referidas al perfeccionamiento de los órganos del Poder Popular es el punto de arranque del proceso de Reforma Constitucional que culmina el 12-6-92, cuando se aprueba la Ley de Reforma Constitucional.

La Comisión organizadora del IV Congreso del Partido, poco después de su constitución el 26 de mayo de 1990, decidió la creación de una Comisión para estudiar el perfeccionamiento de los órganos del Poder Popular, integrada por Diputados, delegados, dirigentes nacionales, provinciales y municipales del Poder Popular, cuadros de funcionarios de la Administración Central del Estado y del aparato auxiliar del Comité Central del Partido.

En el mes de julio, por sugerencia de Fidel Castro, esta Asamblea adoptó el Acuerdo III-112, que dispuso: "Encomendar al Presidente de la Asamblea Nacional del Poder Popular la organización y ejecución del

12 Petras, James, F. Morley y Morris H., «El socialismo cubano: la rectificación y el nuevo modelo de acumulación", Cuadernos de Política Internacional, n. ${ }^{9}$ 52, México, 1990.

Mesa-Lago, Carmelo, "El proceso de rectificación en Cuba: causas políticas y económicas", Revista de Estudios Políticos, n. 74, 1991. 
estudio y análisis acerca de la vida y el funcionamiento de los órganos municipales del Poder Popular", el cual se realizó en 35 municipios del país.

Al mismo tiempo, y en cumplimiento de los acuerdos del XI Pleno del Comité Central del Partido, se crearon los Grupos de Consultas Provinciales, integradas por funcionarios estatales, delegados provinciales y municipales, diputados y cuadros del partido, para analizar las opiniones vertidas por la población en el debate en torno al funcionamiento de la democracia socialista.

Dicha Asamblea, en su Acuerdo III-132, de 5 de julio de 1991, consideró que se hacía inaplazable la necesidad de extender el periodo de mandato de los órganos del Poder Popular, teniendo en cuenta que el tiempo que restaba no era suficiente para preparar el estudio de las decisiones que se requerian para perfeccionar los aspectos relacionados con la estructura, sobre los órganos de dirección y llevar a cabo las modificaciones imprescindibles en la Constitución, elaborar una nueva Ley Electoral y las Normas Reglamentarias del sistema de órganos del Poder Popular.

Como resultado de todo este estudio se elaboró el proyecto de "Resolución sobre el perfeccionamiento de la organización y funcionamiento de los órganos del Poder Popularn, que fue presentado para su examen y aprobación previa a la Comisión Organizadora del IV Congreso. $Y$ fue ése, el documento que se discutió y aprobó como Resolución, durante el Congreso, en octubre de $1991^{13}$.

La Resolución acordada sobre este tema contiene recomendaciones expresas que conducen directamente a la modificación de determinados preceptos constitucionales. Tal es el caso de la que se refiere a la realización de la elección de los Diputados a la Asamblea Nacional del Poder Popular, y de los Delegados a las Asambleas Provinciales del Poder Popular por el voto directo de los electores.

Asimismo, la mencionada Resolución del IV Congreso recomienda ${ }^{14}$ "considerar en las normas legales correspondientes, la definición del órgano municipal del Poder Popular y el alcance de sus facultades en el marco de la sociedad local, bajo el principio de que el municipio actúa con per-

13 Véase Félix Pérez Maliar, "La Resolución del IV Congreso del Partido sobre el perfeccionamiento de los Órganos del Poder Popular y la Reforma de la Constitución», Revista Cubana de Derecho, n.ำ 7, 1992.

14 Ibidem. 
sonalidad jurídica propia y sus órganos deben responder funcionalmente al principio de inmediatez y que tiene el carácter de organismos y entidades auxiliares del poder que centralmente ejerce el Estado en todo el territorio nacional, realizando además las funciones estatales y de administración de su competencian.

Otras recomendaciones presentes en esa Resolución sugieren: precisar el alcance de las atribuciones del municipio en relación con las entidades radicadas en su territorio que son de otra subordinación; considerar la provincia, de acuerdo con su naturaleza, como el eslabón intermedio entre el gobierno central y el municipal, por lo que sus funciones principales deben ser las de coordinar y controlar en su demarcación, la ejecución de la política y los programas y planes acordados por los órganos superiores del Estado; diferenciar en la provincia y en los municipios, orgánica y funcionalmente, los órganos estatales de carácter representativo de los órganos ejecutivo-administrativos, delimitando claramente el ámbito de sus funciones y relaciones. Todas ellas conducen, necesariamente, a una exhaustiva revisión del Capítulo IX de la Constitución, que trata de los Órganos Locales del Poder Popular.

Estas recomendaciones, precedidas del cuidadoso examen de los planteamientos formulados por la población en la discusión al Llamamiento al IV Congreso del Partido, referido al Poder Popular, y la evaluación de la experiencia del funcionamiento de estas instituciones, requerían de su expresión constitucional para dar paso al propósito perfeccionador de los mencionados órganos, y urgían su continuación en los necesarios cambios que habia de realizarse en la legislación electoral y en la que reglamenta la organización y funcionamiento de las Asambleas del Poder Popular y de los órganos administrativos que éstas crean.

Lo acordado en la Resolución del IV Congreso del partido sobre el perfeccionamiento de los Órganos del Poder Popular, que promueve la introducción en la constitución de las enmiendas correspondientes a dicho órganos, no finaliza al abordar esta cuestión. La Resolución recomienda, además, que en los estudios de la Constitución se incluyan otros aspectos de su texto no relacionados propiamente con el propósito de perfeccionar los Órganos del Poder Popular, pero que pueden estar requeridos de actualización o de precisiones.

Por ello en el acuerdo final de la Resolución se dispone la creación de una Comisión para que auxilie al Comité Central con el propósito de "conocer, analizar y valorar adecuadamente, durante el proceso de su conformación, los proyectos legislativos y otras medidas legislativas y organizativas que preparen $y$ adopten para la materialización de los objetivos planteados en esta Resolución". 
A partir de ese momento, la Comisión de la Asamblea Nacional procedió a un análisis del texto de la Constitución para elaborar un primer texto o proyecto de las modificaciones, y finalmente se redactó un último documento que fue el que se distribuyó a todos los Diputados de la Asamblea Nacional, a los miembros del Comité Central y a los jefes de los organismos de la Administración Central del Estado.

\section{LA LEY DE REFORMA CONSTITUCIONAL}

El proyecto de reforma constitucional fue convertido en Ley por la aprobación unánime de los diputados de la Asamblea Nacional (12-6-92). Aunque como analizaremos a continuación, si bien han sido numerosas las modificaciones que ha sufrido el texto, esto no significa que haya ahora una nueva Constitución, ya que dichas modificaciones no afectan a la parte dogmática, es decir, los derechos y deberes de los ciudadanos consagrados en la Constitución, ni a la integración y facultades de la Asamblea Nacional o de su Consejo de Estado. Por esta misma razón, estas modificaciones no han necesitado seguir el procedimiento que requiere un referéndum posterior a la aprobación. Ha bastado el procedimiento más sencillo que incluye el artículo 141, es decir, basta acuerdo adoptado por la Asamblea Nacional, en votación nominal, por una mayoría no inferior a las dos terceras partes del número total de sus integrantes.

No han faltado opiniones que ante tal número de modificaciones como se han llevado a cabo, hubieran considerado más idóneo el redactar un nuevo texto, pero el momento político y económico es extraordinariamente grave, y el "período especial" no aconsejaba un proceso de la envergadura de una reforma total del texto.

Veamos a continuación las modificaciones más significativas introducidas en la Constitución de la República, aprobadas en la Ley de Reforma Constitucional el 12-6-92. Están dirigidas fundamentalmente a:

Cap. I: "Fundamentos Políticos, Sociales y Económicos del Estado". En el artículo 1 se incluye la definición del Estado Socialista a todos los segmentos de la sociedad, al plantearse que Cuba es un Estado Socialista de trabajadores, independiente y soberano, organizado con todos y para el bien de todos.

El artículo 7 elimina la enumeración rígida de las organizaciones sociales y de masas, y enuncia estos elementos como categoría del sistema político, forma que permite la adaptación a las nuevas condiciones que se producen en el desarrollo de nuestra sociedad. 

religiosa.

El artículo 8 reconoce, respeta y garantiza expresamente la libertad

El artículo 12 destaca dentro de los principios del Estado Cubano la integración económica y política de Cuba a los países de América Latina y el Caribe.

El artículo 18 señala que el Estado dirige y controla el comercio exterior, pero esto deja de ser función exclusiva del Estado.

El artículo 23 reconoce una nueva forma de propiedad, la de las empresas mixtas, sociedades $y$ asociaciones económicas que se constituyen con arreglo a la Ley.

Artículo 68: establece que la organización y funcionamiento de los órganos estatales se integran y desarrollan su actividad sobre el principio de la Democracia Socialista; en este principio se subsume el Centralismo Democrático y la Unidad de Poder. Se elimina la doble subordinación de los órganos ejecutivo-administrativos.

Se incorpora el Capítulo Ill sobre extranjería.

Se incorpora el Capítulo VIII, "Estado de Emergencia».

Se incorpora el Capitulo XI, denominado "La División Político Administrativan; en su artículo 102 se define la Provincia y el Municipio como la sociedad local con personal juridica.

En el Capítulo XII, "Los Órganos Locales del Poder Popular", en su artículo 103 se reconoce la creación de las Administraciones Locales (nuevos órganos administrativo-ejecutivos) y los Consejos Populares.

Artículo 105: entre las atribuciones de las Asambleas Provinciales está la de designar al Secretario de la Asamblea; en la actualidad no es un cargo electivo. Así como la de controlar y fiscalizar la actividad del Órgano de Administración de la Provincia y designar y destituir a sus miembros (este órgano sustituye al anterior Comité Ejecutivo).

Artículo 106: las Asambleas Municipales tienen entre sus atribuciones la de designar al Secretario de la Asamblea en esta instancia. Además, controlar y fiscalizar la actividad del Órgano de Administración Mu- 
nicipal, designar y sustituir a sus miembros (este órgano sustituye al anterior Comité Ejecutivo Municipal, en la actualidad no es un órgano representativo de la Asamblea). Se separan los órganos representativos de los ejecutivo-administrativos.

Artículo 111: se amplía el término de mandato para las Asambleas Provinciales a 5 años. Se mantiene el término de mandato para las Asambleas Municipales por 2 años y medio.

Artículo 114: establece las obligaciones de los delegados a las Asambleas Municipales.

Artículo 115: enuncia los deberes esenciales de los delegados a las Asambleas Provinciales del Poder Popular.

Artículo 117: establece que los Presidentes de las Asambleas Provinciales y Municipales del Poder Popular son a su vez Presidentes de los respectivos Órganos de Administración y representan al Estado en sus demarcaciones territoriales.

Capítulo XIV, «Sistema Electoral»: en el artículo 131 y siguientes se reconoce el derecho de los ciudadanos a intervenir en la dirección del Estado, bien directamente o por intermedio de sus representantes. Se establece la elección directa de los delegados municipales y provinciales, y de los diputados.

\section{LA NUEVA LEY ELECTORAL 72/92}

El sistema electoral cubano ha estado regulado inicialmente en el texto constitucional de la República del 24-2-76, la Ley Electoral 1.305, del 7-7-76, derogada posteriormente por la Ley 37, de 15-8-82, y las Leyes 55 y 56, de 1986, que regularon las elecciones que se produjeron desde la constitución de los órganos representativos en el año 1976, antes de adoptarse la Ley de Reforma Constitucional de julio de 1992, y la nueva Ley Electoral 72 de octubre de 1992. Dado que el texto legal es muy extenso, comentaremos algunas de las novedades que presenta y que han justificado la nueva ley.

Tanto en la Constitución como en la Ley Electoral derogada, se establece que el voto es libre, igual y secreto, y estas características se re- 
conocen expresamente en la Ley Electoral vigente. Respecto a la libertad de voto, efectivamente no hay ningún mecanismo legal que obligue a ello, pero en la realidad se podría hablar de una cierta coacción psicológica, y un cierto control, a juzgar por los resultados de las votaciones de las últimas elecciones municipales ${ }^{15}$. Aunque jurídicamente hay que subrayar que el sufragio se considera un derecho del ciudadano, y no una obligación jurídica.

En la Ley Electoral vigente se incorpora como elemento nuevo el principio de Ética Electoral ${ }^{16}$. En este capítulo se regula la línea de actuación de los candidatos nominados, que upodrán participar de conjunto en actos, conferencias $y$ visitas de trabajo para facilitar su conocimiento por los electores".

Uno de los cambios que recoge la nueva ley es el referido a la integración y atribuciones de las Comisiones de Candidaturas en el Título IV. Hasta ahora, estas Comisiones encargadas de elaborar las propuestas de candidaturas estaban presididas por un representante del Partido Comunista de Cuba; en cambio, ahora están presididas de acuerdo con la nueva Ley Electoral por un representante de los trabajadores organizados en la Central de Trabajadores de Cuba, por miembros de los Comités de Defensa de la Revolución, de la Federación de Mujeres Cubanas, de la Asociación Nacional de Agricultores Pequeños, de la Federación de Estudiantes de la Enseñanza Media, para lograr de esta forma la representación de todos los miembros de las sociedades: trabajadores, mujeres, campesinos y jóvenes ${ }^{17}$.

Los Comités Ejecutivos Provinciales y Municipales antes de la reforma contenían una doble naturaleza puesto que eran órganos representativos, ya que sus miembros se elegían del seno de la Asamblea y por otra parte eran órganos de gestión en su condición de órganos administrativo-ejecutivos. Esta doble naturaleza de los Comités Ejecutivos limitó el ejercicio de la labor de las Asambleas del Poder popular, ya que en realidad el ejecutivo dirigía la actividad del órgano de poder. En los cambios y reformas llevadas a cabo en el proceso llamado de "perfeccionamiento de las instituciones", uno de los objetivos marcados es el fortalecer la labor de las asambleas del Poder Popular en to-

15 Elecciones municipales. Véase: Prensa internacional de 28-2-93 y dias sucesivos. La información generalizada es que votaron el $92,8 \%$ de los ciudadanos cubanos a los candidatos únicos.

${ }_{16}$ El Título $X$ está dedicado al tema: “De la Ética Electoral». Incluye el artículo 171 y representa una innovación en redacción y contenido.

17 Véase: Isabel Cristina VARONA, "La reforma constitucional...", op. cit. 
das las instancias. Para lograr este propósito es necesario que las Asambleas, como máximos órganos estatales en sus demarcaciones respectivas, se apoyen más en las Comisiones de Trabajo. Las modificaciones realizadas a este respecto en la parte orgánica de la constitución están dirigidas a diferenciar en la Provincia y en el Municipio, tanto orgánica como funcionalmente, los órganos estatales de carácter superlativo (Asambleas Locales del Poder Popular) de los ejecutivo-administrativos (actuales órganos de administración), bajo el principio de que ambos órganos son dirigidos por el Presidente de las respectivas Asambleas, con el objetivo de aumentar la autoridad de los delegados y el control de las Asambleas sobre la gestión de las entidades administrativas.

En la nueva Ley Electoral, uno de los cambios más significativos es la elección directa de los delegados municipales, provinciales y de los diputados; el aumento de las facultades de las Comisiones Electorales encaminadas a: eliminar procedimientos formales, en particular en los actos referidos a la constitución de las Asambleas del Poder Popular y la elección de los Comités Ejecutivos, que en adelante serán los Órganos de la Administración, integrado por funcionarios designados por las respectivas Asambleas; ampliar la facultad de las Comisiones de Candidaturas para hacerlas más efectivas; agilizar el procedimiento para organizar por las Comisiones Electorales la sesión constitutiva de las Asambleas y flexibilizar los plazos establecidos para esos procesos.

Para resultar elegido un candidato se mantiene en la nueva Ley Electoral como requisito indispensable el haber obtenido más del $50 \%$ de los votos emitidos. En otro caso, tiene que realizarse una segunda ronda de elecciones entre los dos candidatos que más votos alcancen en la primera, y se considera electo aquel que obtuvo más votos en la segunda vuelta.

Se incluye en la actual Ley, a diferencia de la derogada Ley $37 / 82$, un nuevo requisito para el ejercicio del sufragio activo que consiste en ser residente permanente por un período no menor de 2 años antes de las elecciones y estar inscrito en el registro electoral del municipio donde reside, asimismo estar incluido en la relación de votantes de la circunscripción electoral de su residencia, o en su defecto en una circunscripción electoral especial.

Se establece además otra incapacidad para el ejercicio del sufragio activo referido a los que se encuentran cumpliendo sanción subsidiaria de privación de libertad. 
La nueva Ley Electoral no contiene, a diferencia de la anterior, el proceso de revocación de los elegidos, en los casos en que no respondieron a la confianza depositada en ellos por los electores. La regulación de este proceso estará contenida en la Ley Orgánica de los Órganos del Poder Popular, que será sometida al análisis y aprobación en la IV Legislatura de la Asamblea Nacional en julio de 1993.

Para hacer un breve resumen, la nueva Ley Electoral 72, de octubre de 1992, ha quedado estructurada en doce Títulos, 174 artículos y unas Disposiciones (3) Especiales, Transitorias y Finales. Enunciaremos los Doce Títulos:

Título Preliminar.

Título l: Del Derecho al sufragio.

Título II: De la jurisdicción electoral

Título III: Del Registro de Electores.

Título IV: De las Comisiones de Candidaturas.

Título V: De la formación y presentación de las candidaturas de delegados a las Asambleas municipales y provinciales y de Diputados a la Asamblea Nacional.

Título VI: De las elecciones.

Título VII: De la Constitución de las Asambleas del Poder Popular.

Título VIII: Del modo de cubrir los cargos electivos vacantes de delegado a la Asamblea Municipal.

Título IX: Del referendo.

Título X: De la Ética Electoral

Título XI: De lo ilícito electoral.

Título XII: Del Archivo de los documentos y de la custodia de los Bienes utilizados en los procesos electorales y de referendo.

En este proceso de modificaciones, conducentes, según las declaraciones que lo justifican, a una mayor participación y un perfeccionamiento democrático, la nueva Ley Electoral establece que todos los municipios, con independencia del número de habitantes, deben elegir como mínimo 2 delegados provinciales y 2 diputados a la Asamblea Na- 
cional del Poder Popular. Se pretende así, garantizar la integración de los representantes municipales en los órganos estatales superiores ${ }^{18}$.

\section{CONSIDERACIONES FINALES}

Hasta aqui hemos descrito el proceso de reforma constitucional llevado a cabo en la República Socialista Cubana, además de referirnos a la nueva Ley Electoral. Ciertamente, han sido tan numerosas las modificaciones que cabe preguntarse si no hubiera sido más provechoso una nueva Constitución y prescindir de la de 1976.

Políticos y técnicos constitucionalistas estaban de acuerdo en que eran precisos tales cambios, pero la dificultad del período especial que atraviesa la República ha aconsejado eludir el proceso de una nueva Constitución que resulta especialmente complicado, largo, y crea dificultades de todo orden, incluso económico, si tenemos en cuenta que hubiera sido preciso convocar un referéndum.

Como señala el Presidente de la Asamblea Nacional ${ }^{19}$, "no se ha renunciado a ninguno de los principios que desde hace más de treinta años marcan el rumbo de nuestro proyecto revolucionario". "Cuba es un Estado Socialista", se señala en el artículo 1; incluimos el ideario de José Martí junto a las ideas político-sociales de Marx, Engels y Lenin, como guía del Estado cubano y sus ciudadanos; mantenemos el concepto básico de internacionalismo proletario; se recoge la perspectiva de una más estrecha colaboración de Cuba en el conjunto de la América Latina y el Caribe, y no renunciamos al objeto de construir la sociedad comunistan.

Efectivamente, no supone esta Constitución un rechazo de la actual, pero sí unas innovaciones que pretenden reforzar la participación democrática y representatividad del ciudadano, aunque no se puedan superar las limitaciones de legitimidad democrática que se generan en un sistema de concentración de poder político en un único órgano y la existencia de un Partido Único. Aun así, supone una apertura política y eco-

18 El artículo 14 de la Ley Electoral 72/92 establece asimismo que: “Los Diputados serán elegidos por el voto directo de los electores del Municipio. Sus funciones tienen carácter nacional y su actuación está sujeta únicamente a la Constitución y a la Ley".

19 Discurso del Presidente de la Asamblea, Dr. Escalona, ante la Asamblea Nacional en la presentación del Proyecto de Ley de Reforma Constitucional. 
nómica en algunos aspectos, véase lo referente a la propiedad, a la religión, o los sistemas de explotación de empresas, que, según la aplicación real que a partir de la vigencia de la Constitución tenga, puede modificar la realidad económica, política y social del país.

Una vez más, se pone de manifiesto la interacción entre textos constitucionales y realidad. Hechos y realidades políticas, económicas y sociales, acaecidos muy recientemente, aconsejaban y hacían necesaria una reforma en el Texto constitucional cubano. Ahora sólo cabe esperar que la fuerza de la norma legal se transmita a la sociedad y se lleven a cabo las modificaciones pretendidas y a su vez se produzcan los efectos sociales, económicos y políticos previstos. 